\title{
Charting the Territory: Symptoms and Functional Assessment in Children With Progressive, Non-Curable Conditions*
}

Rose Steele $^{\mathrm{a}}$, RN, PhD; Harold Siden ${ }^{\mathrm{b}, \mathrm{c}}$, MD, MHSc, FRCP; Susan Cadell ${ }^{\mathrm{d}}$, RSW, PhD; Betty Davies $^{\mathrm{e}}, \mathrm{RN}, \mathrm{PhD}, \mathrm{FAAN}$, Gail Andrews ${ }^{\mathrm{c}}, \mathrm{MEd}$; Leanne Feichtinger ${ }^{\mathrm{c}}, \mathrm{BSc}$; Mina Singh ${ }^{\mathrm{a}}, \mathrm{RN}$, $\mathrm{PhD}$

\author{
Affiliations:

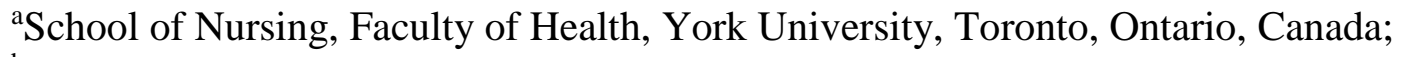 \\ ${ }^{b}$ Department of Paediatrics, University of British Columbia; Canuck Place Children's Hospice, \\ Vancouver, British Columbia, Canada; \\ ${ }^{c}$ Developmental Neuroscience and Child Health, Child \& Family Research Institute, Vancouver, \\ British Columbia, Canada; \\ ${ }^{\mathrm{d} S c h o o l ~ o f ~ S o c i a l ~ W o r k, ~ R e n i s o n ~ U n i v e r s i t y ~ C o l l e g e ~-~ U n i v e r s i t y ~ o f ~ W a t e r l o o, ~ W a t e r l o o, ~}$ \\ Ontario, Canada;

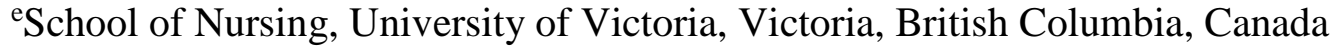

\section{Corresponding Author:} \\ Rose Steele, Professor, School of Nursing, Faculty of Health, York University, Room 342 HNES \\ Building, 4700 Keele Street, Toronto, ON M3J 1P3 Canada. Email: rsteele @yorku.ca; \\ telephone: (416) 736-2100 ext. 40556; fax: (416) 736-5714.
}

Key Words: Palliative Care; Genetics; Metabolic; Neurodisability

\footnotetext{
* This article has been accepted for publication in Archives of Disease in Childhood following peer review. The definitive copyedited, typeset version is available online at: http://adc.bmj.com/content/99/8/754.
}

Steele R, Siden H, Cadell S, et al. Charting the territory: Symptoms and functional assessment in children with progressive, non-curable conditions. Arch Dis Child. 2014;99:754-62. doi:

10.1136/archdischild-2013-305246. 


\begin{abstract}
Background: Children with progressive, non-curable genetic, metabolic, or neurological conditions require specialized care to enhance their quality of life. Prevention and relief of physical symptoms for these children needs to begin at diagnosis, yet, little is known about their patterns of symptoms and functional abilities.
\end{abstract}

Aim: To describe these children's symptoms, as well as how the children's condition affects them physically.

Design: Cross-sectional, baseline results from an observational, longitudinal study, Charting the Territory, that followed 275 children and their families.

Setting/participants: Seven tertiary care children's hospitals in Canada, 2 in the USA. Families were eligible based on the child's condition. A total of 275 children from 258 families participated.

Results: The 3 most common symptoms in these children were pain, sleep problems, and feeding difficulties; on average, they had 3.2 symptoms of concern. There was a pattern of underreporting of children's symptoms for clinicians compared with parents. Regardless of use of associated medications, pain, feeding, and constipation symptoms were often frequent and distressing. Children with a $\mathrm{G} / \mathrm{J}$ tube had a higher total number of symptoms, and respiratory problems, pain, feeding difficulties, and constipation were more likely to occur. They also tended to have frequent and distressing symptoms and to need extensive mobility modifications, which in turn was associated with higher numbers of symptoms.

Conclusions: These children experience multiple symptoms that have been previously documented individually, but not collectively. Effective interventions are needed to reduce their symptom burden. Future longitudinal analyses will examine which disease-modifying interventions improve, or not, symptom burden. 
Children with progressive genetic, metabolic, or neurological conditions for which there is no cure (PNCs) and their families require specialized care to enhance their quality of life. In Canada, about half of the annual 2500 childhood non-traumatic deaths occur because of PNCs. [1,2] These diagnoses account for more than $50 \%$ of children who receive pediatric palliative care in North America. $[1,3,4]$ Though individual conditions are rare, they have been broadly categorized within a single group because of their unifying problem: they involve impairment/injury of the central nervous system and are progressive.[5,6] These children typically display problems seen with such impairment, e.g., pain, seizures, and loss of mobility,[7] therefore prevention and relief of physical symptoms needs to begin at diagnosis. Yet, little is known about the patterns of symptoms or possible correlations with functional abilities.

Research in pain and symptom management is a priority in pediatric palliative care,[8] and families of children with PNCs report symptoms and issues around medications as two important milestones in a child's illness trajectory.[6] Common symptoms reported by clinicians include: pain, breathing problems, feeding difficulties, alertness/interaction changes, sleep problems, seizures, and constipation.[3,7,9-22] There is a need to research children's symptoms, but information about symptoms is not always documented even in patient records[4] and the cooccurrence of symptoms is rarely explored. Children may be prescribed multiple medications, [3,20-24] but little is published about the specific types of medications commonly used by clinicians and whether or not the prescribed medications alleviate symptoms.

These children usually experience developmental delays and functional losses that increase over time. $[6,9,25]$ There is some evidence that pain behaviour may be different for children with neurodegenerative conditions,[25] but the literature is inconsistent regarding 
whether functional levels affect pain expression.[26,27] The relationships between functional levels and other symptoms remain unclear, yet loss of mobility and needing modifications/equipment are significant milestones in this population.[6]

Many children with PNCs receive enteral feeds, e.g., via gastrostomy or jejunal (G/J) tubes.[6,24] Improved nutrition can lead to improved quality of life for the child and family,[28] but $\mathrm{G} / \mathrm{J}$ feeding can result in complications such as aspiration pneumonia, site infection, and reflux.[22,28] Consequently, the children may have related symptoms, e.g., pain, feeding or respiratory problems, but little is known about correlations between $\mathrm{G} / \mathrm{J}$ feeds and symptoms. Further, clinical experience suggests that children with G/J tubes often have restricted mobility, which may contribute to increased symptoms. Exploration of this anecdotal evidence is warranted.

Overall, there is a paucity of research on which to base best practices for care of children with PNCs.[3,29] Much of the fairly limited literature focuses on specific conditions.[9$15,30,31]$ Discussion is often about the treatment of one symptom such as seizures.[9,16] A majority of the research is retrospective[13,14,30] and often the sample sizes are small.[9,10,15] Though some information has been published, there is little to describe the natural progression of this group as a whole, particularly from a prospective approach. Little information exists about differences in symptoms by physical functioning, e.g., by the need for mobility modifications or presence/absence of a $\mathrm{G} / \mathrm{J}$ tube.

This paper reports baseline results about 275 child participants (from 258 families) in a multisite, longitudinal study, Charting the Territory, that followed children with these conditions, and their families. The focus is on symptoms reported, and differences in selected symptoms by use of medications, G/J tube presence, and/or level of mobility modifications. 


\section{METHODS}

The larger study was developed to determine the child's clinical trajectory including symptoms, and the associated emotional, social, physical, and spiritual experiences of the family over time. It used quantitative methods, with established instruments and record reviews. Children (0-19 years) and their families were followed for 18-48 months, depending on when they entered the study. Data collection began at baseline and continued through bereavement or until the end of study.[1]

\section{Recruitment}

Families were recruited from July 2009 till October 2012, mostly through referrals from hospital clinics (49\%) and hospice/palliative teams/services (43\%). Eligibility was based on the child's condition (Appendix A, Web only). Of 385 families evaluated for eligibility, 93 did not meet criteria or declined further contact, 34 could not be contacted, leaving 258 families.

\section{Data Collection}

To facilitate continuity and reduce the likelihood of inter-rater discrepancies, parents identified a 'designated' parent in their family to answer questions about the child. Designated parents completed baseline questionnaires in-person, by mail, or a combination thereof and, subsequently, reported on their child's symptoms monthly via the Internet or, for a few, by telephone. Parents who chose the online method needed to have an existing email account and access to the Internet. The software included an email component every month to prompt parents to visit the secure website and complete the symptom questionnaire. A Research Assistant (RA) called telephone responders to obtain answers.

\section{Record review}


After enrollment, the site RA collected baseline information regarding the child's diagnosis, clinical condition, medications, and procedures undergone. Disease diagnoses were characterized according to a scheme developed in an iterative process by one of the authors (HS) and 2 study collaborators from Biochemical Diseases/Genetics and Pediatric Neurology.

\section{Clinical symptoms}

Information about 7 common symptoms in this population was collected at baseline and then monthly. Parents were given definitions for each symptom - pain, respiratory/breathing problems, feeding difficulties, alertness/interaction changes, sleep problems, seizures, and constipation - prior to completing the baseline assessment (Appendix B, Web only).

The instrument takes 6 to 10 minutes to complete and was designed by the research team in consultation with other experienced clinicians, families linked to a pediatric palliative care hospice program, and a psychometrician. It is a modification of the PediQUEST symptom recording tool and the revised Memorial Symptom Assessment Scale (7-12 years of age) developed for symptoms in children with cancer.[32] Symptoms are tracked for timing of onset (symptom latency[15]), frequency in last week, change since first appeared (or since previous month), and extent of distress. Face and content validity were evaluated prior to the start of the study with the assistance of parents of children who received palliative care, and the instrument was pilot tested in clinical practice (HS).

\section{Annual functional assessment: Pediatric Evaluation of Disability Inventory (PEDI ${ }^{\odot}$ )}

The $\operatorname{PEDI}^{\Theta}[33,34]$ was used to assess the children's function at baseline, then annually. It yields information under Parts I (Functional Skills), II (Caregiver Assistance), and III (Modifications) in the domains of self-care, mobility, and social function. Scores are summarized into composite scores. Raw scores from Parts I and II can be converted to normative standard 
scores as well as scaled scores for comparison against norm-age values. Raw scores are reported for this study because children with PNCs tend to have significant disabilities; therefore, it was deemed unreasonable to compare them to 'norms'. Appendix C (Web only) provides details about the reliability and validity of the $\mathrm{PEDI}^{\odot}$, procedures for administering it, and steps taken to ensure RAs were competent in using the instrument.

\section{Data Analysis}

Data were entered into a database for preprocessing, data cleaning, and determination of scale composites according to the appropriate procedures for the standardized measures. Missing data for outcome measures were linearly imputed, if possible, according to standard procedures for the specific tool. Analyses were performed using the Statistical Package for the Social Sciences (SPSS®), Version 20, with statistical significance at $\mathrm{p}<.05$.

Demographics and outcome measures were summarized using descriptive statistics: frequencies and \% for categorical variables, means and SD for continuous variables. Two-tailed comparison tests included: $\chi^{2}$, two-sample t-test, Spearman's Rho and Pearson r correlations, 1way and 2-way ANOVA.

Ethics approval for this bi-national (Canada/USA) study was obtained from 9 study settings plus the 4 universities where the researchers were affiliated. The University of British Columbia and Children's \& Women's Health Centre of BC (Certification \#H08-00124) approved the central site in Vancouver. On behalf of themselves and their child(ren), parent participants signed a consent form; the ill children were unable to sign consent/assent forms due to their health conditions.

\section{RESULTS}

\section{Sample Characteristics}


Few meaningful differences were detected by study site across all analyses, therefore, results are reported for the whole sample. On average, the 258 families had 2.5 (SD 1.4) living children, range $1-10 ; 283 / 574$ of the total number of children had a PNC, with two such children enrolled from 17 families. Prior to baseline, a total of 20 children in 16 families had died, 50\% from a PNC; of the remainder, 5 were miscarriages. Most families $(n=169,65.5 \%)$ received some form of palliative care.

Families had been engaged with the medical system for over 6 years on average (table 1). They typically waited almost a year between bringing the child to a physician and receiving a diagnosis; though many children still did not have a diagnosis $(n=48,17.5 \%)$. About $30 \%$ of parents learned prenatally $(n=33)$ or perinatally $(n=51)$ that the child had a problem. Others initiated investigation because of concerns such as the child not meeting developmental milestones $(n=54,19.6 \%)$. The child's average age at which parents began the diagnostic process was 12.1 months (SD 25.5). Clinicians typically employed multiple methods for confirming diagnoses.

Records indicated that all children underwent at least one surgery or interventional radiology procedure (table 2). Most had multiple assessments and many took several types of medications (mean 3.5, SD 2.3). Sixty-one percent $(n=168)$ received nourishment other than orally and $13.1 \%(n=36)$ used a ventilator. Many children $(n=125,45.5 \%)$ had an abnormal EEG.

As detailed in table 3, symptoms were common, with about half of the children experiencing any of the symptoms except for difficulties with alertness. Parents reported an average of 3.2 (SD 1.9) symptoms at baseline, whereas clinicians documented fewer (mean 2, SD 1.7). Correlations between parental and clinician reports of symptoms were positive, and weak to moderately strong; all were statistically significant $(\mathrm{p}=<.001)$. 
Parents reported frequency and change for symptoms, as well as the distress they ascribed to the child (table 4). Only two symptoms showed statistically significant differences by conditions: change in seizures $\left(\chi^{2}=35.79, p=.02\right)$, and distress from feeding difficulties $\left(\chi^{2}=38.26\right.$, $\mathrm{p}=.03)$.

The only statistically significant difference between 4 selected symptoms and their associated medication use (table 5) was frequency for seizures $\left(\chi^{2}=11.71, \mathrm{p}=<.01\right)$, though distress was present for the majority who were receiving seizure medications. Regardless of whether medications were used, parents also reported children experiencing and being distressed by pain, feeding difficulties, and constipation.

Children with G/J tubes had more symptoms (mean 3.67, SD 1.74) than children without (mean 2.68, SD 2; $\mathrm{p}=<.001$ ). Differences were seen in breathing, pain, feeding, and constipation symptoms depending on G/J tube presence (table 6). Despite mostly statistically insignificant results, G/J tube presence was generally consistent with higher levels of symptom frequency and distress (table 7).

Table 8 shows that average functional levels were all on the low end of the respective subscales, indicating that children could provide little self-care (mean 14.7, SD 19.6), had difficulty in getting around (mean 14.6, SD 19.2), and were limited in social function (mean 16.9, SD 17.8). All Functional and Caregiver Assistance subscales showed statistically significant differences by conditions $(\mathrm{p}=\leq .001)$.

As shown in table 9, children who scored lower on functional skills had a higher total number of symptoms; children with $\mathrm{G} / \mathrm{J}$ tubes were more likely to require extensive mobility modifications; and both G/J tube presence and level of mobility modification were associated with higher numbers of symptoms, though their interaction was not statistically significant. 


\section{DISCUSSION}

Results from this study are supported by the literature in a number of ways, including the plethora of medications given to these children.[3,16,17] One of the most striking findings is the children's large symptom experience. The children had, on average, just over 3 symptoms of concern and almost every symptom appeared in at least half of the children. This finding in children with metabolic, chromosomal, or neurological conditions parallels findings about symptom burden in children with cancer.[35,36]

Symptom management is a hallmark of pediatric palliative care and it is not surprising that many of the children were being treated for multiple symptoms. However, symptoms were often not well-controlled and children frequently experienced and were distressed by symptoms, whether or not they were receiving associated medications. Where children were receiving an indicated medication, the treatment was often not effective. These findings highlight the difficulties in managing symptoms in this population, especially seizures, and suggest that further research is needed to identify optimal management.

Though there were significant correlations between parent and clinician reports of children's symptoms, there was a pattern of underreporting for clinicians compared with parents, a finding that is consistent with some pediatric palliative care literature. $[7,21,37,38]$ There are many potential reasons for this finding, including missing documentation.[4] One reason may be that neurological symptoms especially are difficult to deal with in this population.[23] Another is that clinicians sometimes report only those symptoms that they feel confident in treating[7] or they do not assess for a symptom because of the child's impaired cognition,[21] and, finally, sometimes clinicians disbelieve parents, especially if a child is non-verbal.[38] Clinicians whose approach is to question why they should not believe a parent rather than why they should and 
who view symptoms as multidimensional experiences that have meaning for patients and their families rather than simply as side effects may be less likely to underreport.[7,38] Also, many anxieties/difficulties accompany parents dealing with PNCs.[6]. If a symptom causes parental concern then parents may report it more frequently.[39] Therefore, clinicians should ask parents why a symptom is of concern so they can address the parents' needs. From a clinical perspective, it is equally important to be cognizant of both the frequency and the severity of symptoms as each may lead to a different understanding of the nature of a symptom, and, therefore, may contribute to identifying the most appropriate intervention.

The increased pattern of symptom burden when a G/J tube is present and/or when there are extensive mobility modifications indicates that clinicians need to be alert to assessing and managing symptoms in these children. We do not know whether feeding devices or mobility tools increase symptoms directly, but both interventions are indicative of children with more severe conditions and, consequently, more symptom burden. Therefore, extra attention to symptoms in children with feeding devices and/or mobility modifications is warranted.

\section{Limitations}

A main limitation of this report is its cross-sectional, primarily descriptive nature. But these are only the first results from a longitudinal study. Future analyses of data, for example examining correlations among variables and over time, will provide a better understanding of changing outcomes as the child's illness trajectory unfolds. Another limitation is that parents reported on behalf of their child. However, this population of children with PNCs is typically non-communicative and parents usually speak for their child in everyday situations. Therefore, it may be reasonable to expect parents rather than these children to provide information. 
A limitation of the PEDI@ in a population with a high level of neurological impairment is that it does not indicate other functional limitations that can impact health, such as respiratory decline and earlier death correlating with a child's inability to hold his head up when prone. However, an important point to note is that a functional assessment can highlight a child's deterioration over time or it can point out when an intervention may be warranted. Routine evaluation of functioning over time would not only document a condition's trajectory, but would also identify places for clinical intervention, as well as provide comparative data about an individual child over time.

\section{CONCLUSIONS}

Pediatric palliative care is an expanding field, yet the paucity of research means that clinicians have little evidence on which to base their practice. This baseline report from a unique longitudinal study offers detailed information about symptoms in children with progressive, noncurable genetic, metabolic, or neurological conditions. The large sample size lends credence to findings and provides a solid foundation for understanding trajectories over time. Future longitudinal analyses will examine which disease-modifying interventions improve, or not, symptom burden.

Acknowledgments: The primary study was supported by the Canadian Institutes of Health Research Grant MOP-89984.

The authors would like to thank all the children and families who participated in the study. We also thank the research assistants in each study setting for their contribution to data collection.

We appreciate that the terminology is not settled regarding the most appropriate term to use when reporting on children with the types of conditions in this study. Various terms, such as lifethreatening, life-limiting, life-shortening, and complex medical problems, have all been proposed and often one is preferred over another depending on one's country. For the purposes of this paper, we have used the term 'progressive, non-curable conditions' because it reduces ambiguity and is acceptable to this journal. 
Financial disclosure: The authors have no financial relationships relevant to this article to disclose.

Conflicts of interest: The authors have no conflicts of interest to disclose.

Funding source: External funding was secured from the Canadian Institutes of Health Research, Canada; MOP 89984.

Writing Assistance: The authors attest that no writing assistance was provided for this article. 


\section{What is known about this topic:}

$>$ Progressive, non-curable genetic, metabolic, or neurological conditions involve impairment/injury of the central nervous system.

$>$ Children often have multiple symptoms associated with such impairment, e.g., pain, seizures, and loss of mobility, and need appropriate interventions.

$>$ These children often rely on enteral nutrition, e.g., via G/J tube, and require mobility modifications.

\section{What this study adds:}

$>$ The 3 most common symptoms in these children are pain, sleep problems, and feeding difficulties; on average, they have 3 symptoms of concern.

$>$ Regardless of medication use, seizure, pain, feeding, and constipation issues may be frequent and distressing to these children.

$>$ Children with G/J tubes, lower levels of function, or extensive mobility modification requirements have a higher total number of symptoms. 


\section{REFERENCES}

1. Siden H, Steele R, Brant R, et al. (2010). Designing and implementing a longitudinal study: Charting the Territory. BMC Pediatr 2010;10:67, 12pp.

2. Statistics Canada. Table102-0551 - Deaths and mortality rate, by selected grouped causes, age group and sex, Canada, annual, CANSIM (database). Statistics Canada Web site http://www5.statcan.gc.ca/cansim/a26?lang=eng\&retrLang=eng\&id=1020551\&paSer=\&patt ern $=\&$ stByVal=1\&p1=1\&p2=-1\&tabMode=dataTable $\& c s i d=\# F 6$. Last modified May 31 2013, accessed 2 Sept 2013.

3. Feudtner C, Kang TI, Hexem KR, et al. Pediatric palliative care patients: a prospective multicenter cohort study. Pediatrics 2011;127:1094-1101.

4. Rogers SK, Gomez CF, Carpenter P, et al. Quality of life for children with life-limiting and life-threatening illnesses: description and evaluation of a regional, collaborative model for pediatric palliative care. Am J Hosp Palliat Care 2011;28:161-170.

5. Association for Children with Life-Threatening or Terminal Conditions and their Families (ACT). A Guide to the Development of Children's Palliative Care Services. 3ed ed. Bristol, UK: ACT/RCPCH 2009.

6. Wood F, Simpson S, Barnes E, Hain R. Disease trajectories and ACT/RCPCH categories in paediatric palliative care. Palliat Med 2010;24:796-806.

7. Rajapakse D, Comac M. Symptoms in life-threatening illness: overview and assessment. In: Goldman A, Hain R, Liben S, eds. Oxford Textbook of Palliative Care for Children. 2nd ed. Oxford, UK: Oxford University Press; 2012:167-177.

8. Steele R, Bosma H, Johnston MF, et al. Research priorities in pediatric palliative care: a Delphi study. J Palliat Care 2008;24:229-239. 
9. Patel NC, Davenport RD, Patel HN. Treatment of seizures in a patient with Batten's disease. Nurse Pract 2008;33:6-7, 9.

10. Phoenix C, Schaefer AM, Elson JL, et al. A scale to monitor progression and treatment of mitochondrial disease in children. Neuromuscul Disord 2006;16:814-820.

11. Verity CM, Winstone AM, Stellitano L, et al. The clinical presentation of mitochondrial diseases in children with progressive intellectual and neurological deterioration: a national, prospective, population-based study. Dev Med Child Neurol 2009;52:434-440.

12. Meyer A, Kossow K, Gal A, et al. Scoring evaluation of the natural course of mucopolysaccharidosis type IIIA (Sanfilippo syndrome type A). Pediatrics 2007;120:e1255e1261.

13. Derks TGJ, Reijngoud D-J, Waterham HR, et al. The natural history of medium-chain acyl COA dehydrogenase deficiency in the Netherlands: clinical presentation and outcome. $J$ Pediatr 2006;148:665-670.

14. Kishnani PS, Hwu W-L, Mandel H, et al. A retrospective, multinational, multicenter study on the natural history of infantile-onset Pompe disease. J Pediatr 2006;148:671-676.

15. Maegawa GH, Stockley T, Tropak M, et al. The natural history of juvenile or subacute GM2 gangliosidosis: 21 new cases and literature review of 134 previously reported. Pediatrics 2006;118:e1550-62.

16. Wusthoff CJ, Shellhaas RA, Licht DJ. Management of common neurologic symptoms in pediatric palliative care: seizures, agitation, and spasticity. Pediatr Clin North Am 2007;54:709-733. 
17. Ho C, Straatman L. A review of pediatric palliative care service utilization in children with a progressive neuromuscular disease who died on a palliative care program. J Child Neurol 2013;28:40-44.

18. Malcolm C, Forbat L, Anderson G, et al. Challenging symptom profiles of life-limiting conditions in children: a survey of care professionals and families. Palliat Med 2011;25:357364.

19. Malcolm C, Hain R, Gibson F, et al. Challenging symptoms in children with rare life-limiting conditions: findings from a prospective diary and interview study with families. Acta Pediatr 2012;101:985-992.

20. Herbert A, Seton C, Gamble A. Sleep and insomnia. In: Wolfe J, Hinds PS, Sourkes BM, eds. Textbook of Interdisciplinary Pediatric Palliative Care. Philadelphia, PA: Elsevier Saunders; 2011:272-283.

21. Collins JJ, Berde CB, Frost JA. Pain assessment and management. In: Wolfe J, Hinds PS, Sourkes BM, eds. Textbook of Interdisciplinary Pediatric Palliative Care. Philadelphia, PA: Elsevier Saunders; 2011:284-299.

22. Friedrichsdorf SJ, Drake R, Webster ML. Gastrointestinal symptoms. In: Wolfe J, Hinds PS, Sourkes BM, eds. Textbook of Interdisciplinary Pediatric Palliative Care. Philadelphia, PA: Elsevier Saunders; 2011:311-334.

23. Hain E, Douglas H. Neurological symptoms. In: Wolfe J, Hinds PS, Sourkes BM, eds. Textbook of Interdisciplinary Pediatric Palliative Care. Philadelphia, PA: Elsevier Saunders; 2011:239-250.

24. Shaw TM. Pediatric palliative pain and symptom management. Pediatr Annals 2012;41:329334. 
25. Breau L, Camfield C, Camfield P. Development and initial validation of the Batten's Observational Pain Scale: a preliminary study. J Pain Manage 2010;3:283-292.

26. Breau LM, Camfield CS. The relation between children's pain behaviour and developmental charactersitics: a cross-sectional study. Dev Med Child Neurol 2010;53:e1-e7.

27. Breau L, Camfield C, Camfield P. The pain behaviour of children with neuronal ceroid lupofiscinosis: variation due to child factors and pain history. J Pain Manage 2010;3:293300.

28. Thompson A, Macdonald A, Holden C. Feeding in palliative care. In: Goldman A, Hain R, Liben S, eds. Oxford Textbook of Palliative Care for Children. 2nd ed. Oxford, UK: Oxford University Press; 2012:284-294.

29. Ullrich C, Morrison R S. Pediatric palliative care research comes of age: what we stand to learn from children with life-threatening illness. J Palliat Med 2013;16:334-336.

30. Noorda G, Hermans-Peters M, Smeitink J, et al. Mitochondrial disease: needs and problems of children, their parents and family. a systematic review and pilot study into the need for information of parents during the diagnostic phase. J Inherit Metab Dis 2007;30:333-340.

31. Wasserstein MP, Desnick RJ, Schuchman EH, et al. The natural history of Type B NiemannPick disease: results from a 10-year longitudinal study. Pediatrics 2004;114:E672-e677.

32. Dussel V, Aldridge SE, Kang T, et al. Feasibility of Conducting a Randomized Controlled Trial (RCT) in Children With Advanced Cancer: Lessons From the Pediatric Quality of Life and Evaluation of Symptoms Technology (PediQuest) Study. Salt Lake City, UT: American Academy of Hospice and Palliative Medicine 2007.

33. Haley M, Coster W, Ludlow L, et al. Pediatric Evaluation of Disability Inventory (PEDI). Boston, MA: Trustees of Boston University 1998. 
34. Berg M, Jahnsen R, Frǿslie KF, et al. Reliability of the Pediatric Evaluation of Disability Inventory (PEDI). Phys Occup Health Pediatr 2004;24:61-77.

35. Heath JA, Clarke NE, Donath SM, et al. Symptoms and suffering at the end of life in children with cancer: an Australian perspective. Med J Aust 2010;192:71-75.

36. Theunissen JMJ, Hoogerbrugge PM, van Achterberg T, et al. Symptoms in the palliative phase of children with cancer. Pediatr Blood Cancer 2007;49:160-165.

37. Hunt A. Pain assessment. In: Goldman A, Hain R, Liben S, eds. Oxford Textbook of Palliative Care for Children. 2nd ed. Oxford, UK: Oxford University Press; 2012:204-217.

38. Hauer JM, Faulkner, KW. Neurological and neuromuscular conditions and symptoms. In: Goldman A, Hain R, Liben S, eds. Oxford Textbook of Palliative Care for Children. 2nd ed. Oxford, UK: Oxford University Press; 2012:295-308.

39. Pritchard M, Burghen EA, Gattuso JS, et al. factors that distinguish symptoms of most concern to parents from other symptoms of dying children. J Pain \& Symptom Manage 2010;39:627-636. 


\section{Licence for Publication Statement}

The Corresponding Author has the right to grant on behalf of all authors and does grant on behalf of all authors, an exclusive licence (or non-exclusive for government employees) on a worldwide basis to the BMJ Group and co-owners or contracting owning societies (where published by the BMJ Group on their behalf), and its Licensees to permit this article (if accepted) to be published in Archives of Disease in Childhood and any other BMJ Group products and to exploit all subsidiary rights, as set out in our licence.

\section{Contributor Statement}

Gail Andrews: Ms. Andrews conceptualized and designed the study, analysed and interpreted the data, revised the resubmitted manuscript, and approved the resubmitted manuscript.

Susan Cadell: Dr. Cadell conceptualized and designed the study, revised the resubmitted manuscript, and approved the resubmitted manuscript.

Betty Davies: Dr. Davies conceptualized and designed the study, revised the resubmitted manuscript, and approved the resubmitted manuscript.

Leanne Feichtinger: Ms. Feichtinger analysed and interpreted the data, revised the resubmitted manuscript, and approved the resubmitted manuscript.

Hal Siden: Dr. Siden conceptualized and designed the study, analysed and interpreted the data, revised the resubmitted manuscript, and approved the resubmitted manuscript.

Mina Singh: Dr. Singh analysed and interpreted the data, revised the resubmitted manuscript, and approved the resubmitted manuscript.

Rose Steele: Dr. Steele conceptualized and designed the study, analysed and interpreted the data, drafted and revised the resubmitted manuscript, and approved the resubmitted manuscript. 
Table 1: Selected Demographic Information at Baseline About 275 Children With Progressive, Non-Curable Conditions (PNCs)

\begin{tabular}{|c|c|}
\hline Demographic & Ill Children \\
\hline \multicolumn{2}{|l|}{ Gender } \\
\hline Female & $139(50.5)$ \\
\hline Male & $136(49.5)$ \\
\hline Age (years) on entry to study & $\begin{array}{l}6.6 \pm 5.2^{\mathrm{a}} \\
0 \text { to } 19\end{array}$ \\
\hline Age (months) at initiation of diagnostic evaluation $(n=261)$ & $\begin{array}{l}12.1 \pm 25.5 \\
-5.8 \text { to } 183.5^{\mathrm{a}, \mathrm{b}}\end{array}$ \\
\hline Age (years) at diagnosis $(n=203)$ & $\begin{array}{l}2.2 \pm 3 \\
-0.4 \text { to } 15.7^{\mathrm{a}, \mathrm{b}}\end{array}$ \\
\hline \multicolumn{2}{|l|}{ New vs. Pre-existing condition $(n=258)$} \\
\hline New (<6 weeks) & $3(1.2)$ \\
\hline Pre-existing ( $\geq 6$ weeks) & $255(98.8)$ \\
\hline \multicolumn{2}{|l|}{ Top concerns that brought parent to $\mathrm{MD}^{\mathrm{c}}$} \\
\hline Not meeting developmental milestones & $54(19.6)$ \\
\hline Perinatal: diagnosis or problem noted & $51(18.5)$ \\
\hline Seizures & $47(17.1)$ \\
\hline Change in muscle tone & $34(12.4)$ \\
\hline Prenatal: diagnosis or problem noted & $33(12)$ \\
\hline Feeding difficulties & $30(10.9)$ \\
\hline Breathing difficulties & $21(7.6)$ \\
\hline Losing developmental milestones & $21(7.6)$ \\
\hline Weeks since parent first sought medical treatment $(n=261)$ & $\begin{array}{r}315.2 \pm 248.9 \\
7.9 \text { to } 980^{\mathrm{a}}\end{array}$ \\
\hline Weeks since child's diagnosis $(\mathrm{n}=203)$ & $\begin{array}{r}269.6 \pm 231.3 \\
0 \text { to } 903.7^{\mathrm{a}}\end{array}$ \\
\hline $\begin{array}{l}\text { Months from initial diagnostic evaluation to confirmation of } \\
\text { diagnosis }(\mathrm{n}=197)\end{array}$ & $\begin{array}{l}11.9 \pm 23.6 \\
0 \text { to } 177.9^{\mathrm{a}}\end{array}$ \\
\hline \multicolumn{2}{|l|}{ Diagnostic methods $^{\mathrm{d}}$} \\
\hline Molecular & $192(69.8)$ \\
\hline Clinical & $178(64.7)$ \\
\hline Biochemistry & $142(51.6)$ \\
\hline Anatomic pathology & $61(22.2)$ \\
\hline \multicolumn{2}{|l|}{ Primary condition } \\
\hline Multi-organ congenital abnormalities & $57(20.7)$ \\
\hline Severe neurological impairment - not yet diagnosed & $48(17.5)$ \\
\hline Epileptic encephalopathy/neurodegenerative disease & $44(16)$ \\
\hline Lysosomal/peroxisomal leukodystrophy & $43(15.6)$ \\
\hline Mitochondrial encephalo-/myopathy & $29(10.5)$ \\
\hline Structural CNS abnormalities & $18(6.5)$ \\
\hline Small molecules diseases & $13(4.7)$ \\
\hline Neuromuscular diseases & $10(3.6)$ \\
\hline Other inborn errors of metabolism & $6(2.2)$ \\
\hline Congenital disorders of glycosylation & $4(1.5)$ \\
\hline Other conditions not otherwise specified (NOS) & $3(1.1)$ \\
\hline
\end{tabular}


Values are number (\%) unless otherwise indicated.

a Plus-minus values are means $\pm \mathrm{SD}$; followed by minimum to maximum.

${ }^{\mathrm{b}}$ Negative values reflect prenatal evaluations and diagnoses.

${ }^{\mathrm{c}}$ Some responses not reported in table; overall, numbers totaled more than sample size because some parents provided multiple responses.

${ }^{\mathrm{d}}$ Numbers totaled more than sample size because multiple methods could be documented. 
Table 2: Record Review: Assessments, Interventions, and Medications Prior to Baseline for 275 Children With Progressive, Non-Curable Conditions

\begin{tabular}{|c|c|}
\hline Assessments, Interventions, and Medications & Ill Children \\
\hline \multicolumn{2}{|l|}{ Assessments } \\
\hline PT/OT (n = 274) & $249(90.5)$ \\
\hline Dietician $(n=248)$ & $246(89.5)$ \\
\hline Home nurse $(n=270)$ & $198(72.8)$ \\
\hline \multicolumn{2}{|l|}{ Selected interventions } \\
\hline Gastric or jejunal tube & $148(53.8)$ \\
\hline Oxygen by nasal cannula or mask & $29(10.6)$ \\
\hline Limits of care/Do not attempt resuscitation orders & $42(15.3)$ \\
\hline Routine suctioning & $50(18.4)$ \\
\hline Non-invasive ventilation & $23(8.4)$ \\
\hline Clinical trial & $20(7.3)$ \\
\hline Total parenteral nutrition & $4(1.5)$ \\
\hline Nasogastric tube & $16(5.8)$ \\
\hline Invasive ventilator & $13(4.7)$ \\
\hline Complementary/alternative modalities & $7(2.5)$ \\
\hline Complementary/alternative medications & $6(2.2)$ \\
\hline Surgery or interventional radiology procedures & $275(100)$ \\
\hline Total number prior to baseline & $11.4 \pm 5.5 ; 6-41^{\mathrm{a}}$ \\
\hline \multicolumn{2}{|l|}{ Used with surgery or interventional radiology procedures } \\
\hline General anesthesia & $170(61.8)$ \\
\hline Total number of times anesthesia used & $3.23+4.8 ; 0-36^{\mathrm{a}}$ \\
\hline Sedation & $61(22.2)$ \\
\hline Total number of times sedation used & $0.6 \pm 1.6 ; 0-11^{\mathrm{a}}$ \\
\hline Electroencephalography (EEG) prior to baseline & $149(54.2)$ \\
\hline Total number of EEGs & $2.6+4.1 ; 0-30^{\mathrm{a}}$ \\
\hline Abnormal EEG prior to baseline & $125(45.5)$ \\
\hline \multicolumn{2}{|l|}{ Medications } \\
\hline Total number of different drug categories & $3.5 \pm 2.3 ; 0-12^{\mathrm{a}}$ \\
\hline Anticonvulsants & $152(55.5)$ \\
\hline Antacids & $125(45.6)$ \\
\hline Metabolic & $118(43.1)$ \\
\hline Anxiolytic & $111(40.7)$ \\
\hline Other & $108(39.4)$ \\
\hline Laxatives & $97(35.4)$ \\
\hline Acetaminophen/NSAIDs & $52(19)$ \\
\hline Melatonin/hypnotic & $48(17.5)$ \\
\hline Pro-kinetics & $43(15.8)$ \\
\hline Cardiac & $27(9.9)$ \\
\hline Antispasticity & $27(9.9)$ \\
\hline Neuroleptic & $21(7.7)$ \\
\hline Opiates & $21(7.7)$ \\
\hline Antiemetics & $12(4.4)$ \\
\hline Anesthetics & $3(1.1)$ \\
\hline
\end{tabular}


Values are number (\%) unless otherwise indicated.

a Plus-minus values are means $\pm \mathrm{SD}$; followed by minimum to maximum. 
Table 3: Symptoms Present at Baseline for 275 Children With Progressive, Non-Curable Conditions

\begin{tabular}{|c|c|c|c|c|c|c|}
\hline Symptom & $\begin{array}{l}\text { Reported by } \\
\text { Parents }^{\mathrm{a}}\end{array}$ & $\begin{array}{c}\mathrm{p}^{\mathrm{b}}: \\
\text { conditions }\end{array}$ & $\begin{array}{l}\text { Reported by } \\
\text { Clinicians in } \\
\text { Children's } \\
\text { Records }^{\mathrm{c}}\end{array}$ & $\begin{array}{c}\mathrm{p}^{\mathrm{d}}: \\
\text { conditions }\end{array}$ & $\begin{array}{l}\text { Months Since } \\
\text { Birth for } \\
\text { Symptom to } \\
\text { Appear }^{\mathrm{e}}\end{array}$ & $\begin{array}{c}\mathrm{p}^{\mathrm{f}}: \\
\text { conditions }\end{array}$ \\
\hline Pain & $\begin{array}{c}149(55.2) \\
\underline{\mathrm{r}}_{\mathrm{s}}=.34, \leq .001\end{array}$ & .78 & $67(26)$ & .13 & $45.7 \pm 59.3^{\mathrm{g}}$ & $<.001$ \\
\hline $\begin{array}{l}\text { Sleep } \\
\text { problems }\end{array}$ & $\begin{array}{c}136(50.2) \\
\underline{\mathrm{r}_{\mathrm{s}}}=.33, \leq .001\end{array}$ & .28 & $75(29.1)$ & $<01$ & $31.4 \pm 50.4^{\mathrm{g}}$ & .02 \\
\hline $\begin{array}{l}\text { Feeding } \\
\text { difficulties }\end{array}$ & $\begin{array}{c}130(48) \\
\underline{\mathrm{r}_{\mathrm{s}}}=.38, \leq .001\end{array}$ & .24 & $108(41.7)$ & .42 & $29.9+49.3^{\mathrm{g}}$ & $<.001$ \\
\hline Constipation & $\begin{array}{c}127(47) \\
\underline{\mathrm{r}_{\mathrm{s}}}=.28\end{array}$ & .33 & $72(27.9)$ & .30 & $30.7 \pm 43.1^{\mathrm{g}}$ & $<.001$ \\
\hline $\begin{array}{l}\text { Respiratory or } \\
\text { breathing } \\
\text { problems }\end{array}$ & $\begin{array}{c}126(46.5) \\
\underline{\mathrm{r}_{\mathrm{s}}}=.28, \leq .001\end{array}$ & .37 & $66(25.6)$ & .57 & $46.7 \pm 60.3^{g}$ & $<.001$ \\
\hline Seizures & $\begin{array}{c}109(40.2) \\
\underline{\mathrm{r}_{\mathrm{s}}}=.65, \leq .001\end{array}$ & $<.001$ & $110(42.5)$ & $<.01$ & $34 \pm 49^{g}$ & .001 \\
\hline $\begin{array}{l}\text { Alertness and } \\
\text { interaction } \\
\text { changes }\end{array}$ & $\begin{array}{c}94(34.7) \\
\underline{\mathrm{r}}_{\mathrm{s}}=.24, \leq .001\end{array}$ & .03 & $42(16.3)$ & .61 & $55.4 \pm 61.5^{g}$ & $<.001$ \\
\hline $\begin{array}{l}\text { Total number } \\
\text { of symptoms }\end{array}$ & $\begin{array}{c}3.2+1.9^{\mathrm{g}} \\
\underline{\mathrm{r}_{\mathrm{s}}}=.46\end{array}$ & $<.01$ & $2 \pm 1.7^{g}$ & .02 & & \\
\hline
\end{tabular}

Values are number (\%) unless otherwise indicated.

a $\%$ for parents calculated based on number of parents who responded to the question; $r_{s}$ is the Spearman's Rho result for bivariate correlations between parental and clinician reports, followed by p-value.

${ }^{\mathrm{b}} \chi^{2}$ test was used for categorical variables and 1-way ANOVA was used for the continuous variable to test by children's conditions.

c\% for clinicians calculated based on number of records reviewed by RA.

${ }^{\mathrm{d}} \chi^{2}$ test was used for categorical variables and 1-way ANOVA was used for the continuous variable to test by children's conditions.

${ }^{\mathrm{e}}$ Results predicated on symptom being present.

${ }^{\mathrm{f}} 1$-way ANOVA was used to test continuous variables by children's conditions.

g Plus-minus values are means \pm SD. 
Table 4: Parental Report of Frequency, Change, \& Distress for Symptoms Present at Baseline in 275 Children With Progressive, Non-Curable Conditions

\begin{tabular}{|c|c|c|c|c|c|c|}
\hline Symptom $^{a}$ & Frequency $^{b}$ & $\begin{array}{c}\mathrm{p}^{\mathrm{c}}: \\
\text { conditions }\end{array}$ & Change $^{\mathrm{d}}$ & $\begin{array}{c}\mathrm{p}^{\mathrm{c}}: \\
\text { conditions }\end{array}$ & Distress $^{\mathrm{e}}$ & $\begin{array}{c}\mathrm{p}^{\mathrm{c}}: \\
\text { conditions }\end{array}$ \\
\hline $\begin{array}{l}\text { Pain } \\
(\mathrm{n}=149)\end{array}$ & $\begin{array}{c}4(2.7) ; \\
70(47.3) ; \\
60(40.5) ; \\
14(9.5)\end{array}$ & .31 & $\begin{array}{l}41 \text { (27.5); } \\
33 \text { (22.1); } \\
52 \text { (34.9); } \\
23(15.4)\end{array}$ & .31 & $\begin{array}{c}5(3.4) ; \\
64(43.2) ; \\
69(46.6) ; \\
10(6.8)\end{array}$ & .05 \\
\hline $\begin{array}{l}\text { Sleep } \\
\text { problems } \\
(\mathrm{n}=136)\end{array}$ & $\begin{array}{c}6(4.5) ; \\
39(29.1) ; \\
88(65.7) ; \\
1(0.7)\end{array}$ & .59 & $\begin{array}{c}30(22.4) ; \\
63(47) ; \\
36(26.9) ; \\
5(3.7)\end{array}$ & .52 & $\begin{array}{l}34 \text { (25.4); } \\
38 \text { (28.4); } \\
47 \text { (35.1); } \\
15 \text { (11.2) }\end{array}$ & .14 \\
\hline $\begin{array}{l}\text { Feeding } \\
\text { difficulties } \\
(\mathrm{n}=130)\end{array}$ & $\begin{array}{l}11(8.5) ; \\
35(27.1) ; \\
81(62.8) ; \\
2(1.6)\end{array}$ & .48 & $\begin{array}{c}41(31.5) ; \\
43(33.1) ; \\
43(33.1) ; \\
3(2.3)\end{array}$ & .25 & $\begin{array}{l}26 \text { (20.2); } \\
39 \text { (30.2); } \\
51(39.5) ; \\
13(10.1)\end{array}$ & .03 \\
\hline $\begin{array}{l}\text { Constipation } \\
(\mathrm{n}=127)\end{array}$ & $\begin{array}{c}7(5.5) ; \\
48(37.8) ; \\
72(56.7) ; \\
0 \\
\end{array}$ & .93 & $\begin{array}{c}34(27) ; \\
63(50) ; \\
29(23) ; \\
0\end{array}$ & .37 & $\begin{array}{c}11(8.8) ; \\
36(28.8) ; \\
66(52.8) ; \\
12(9.6)\end{array}$ & .44 \\
\hline $\begin{array}{l}\text { Respiratory or } \\
\text { breathing } \\
\text { Problems } \\
(\mathrm{n}=126)\end{array}$ & $\begin{array}{c}5(4) ; \\
59(47.2) ; \\
60(48) ; \\
1(0.8) \\
\end{array}$ & .83 & $\begin{array}{c}40(32.8) ; \\
37(30.3) ; \\
43(35.2) ; \\
2(1.6)\end{array}$ & .81 & $\begin{array}{c}16(13) ; \\
41(33.3) ; \\
56(45.5) ; \\
10(8.1)\end{array}$ & .20 \\
\hline $\begin{array}{l}\text { Seizures } \\
(\mathrm{n}=109)\end{array}$ & $\begin{array}{c}9(8.3) \\
45(41.3) ; \\
49(45) ; \\
6(5.5)\end{array}$ & .53 & $\begin{array}{c}40 \text { (36.7); } \\
27 \text { (24.8); } \\
38 \text { (34.9); } \\
4 \text { (3.7) }\end{array}$ & .02 & $\begin{array}{l}22 \text { (20.4); } \\
28 \text { (25.9); } \\
42 \text { (38.9); } \\
16 \text { (14.8) }\end{array}$ & .39 \\
\hline $\begin{array}{l}\text { Alertness and } \\
\text { interaction } \\
\text { changes } \\
(\mathrm{n}=94)\end{array}$ & $\begin{array}{c}4(4.3) ; \\
57(62) ; \\
27(29.3) ; \\
4(4.3)\end{array}$ & .66 & $\begin{array}{c}41(44.1) ; \\
22(23.7) ; \\
26(28) ; \\
4(4.3)\end{array}$ & .08 & $\begin{array}{l}28 \text { (30.1); } \\
22 \text { (23.7); } \\
25 \text { (26.9); } \\
18 \text { (19.4) }\end{array}$ & .17 \\
\hline
\end{tabular}

Numbers reported as frequency $(\%)$.

${ }^{\text {a }}$ Sample size for each symptom is the number of times parents reported a symptom was present for their child at baseline.

${ }^{\mathrm{b}}$ Frequency of symptom in last week reported as Almost never; Sometimes; Most of the time; Unsure/Can't tell. \% calculated based on number of parents who responded to the question.

${ }^{c} \chi^{2}$ tests used for all variables by children's conditions; for all comparisons.

${ }^{\mathrm{d}}$ Change in symptom since symptom first appeared reported as Better; About the same; Worse;

Unsure/Can't tell. \% calculated based on number of parents who responded to the question.

e Extent of child's distress from symptom in last week reported as None or a little bit; Somewhat; A lot; Unsure/Can't tell. \% calculated based on number of parents who responded to the question. 
Table 5: Relationships Between Use of Associated Medications and Frequency \& Distress for 4 Selected Symptoms Present at Baseline in 275 Children With Progressive, Non-Curable Conditions

\begin{tabular}{|c|c|c|c|c|c|c|c|c|}
\hline \multirow[t]{2}{*}{ Symptom $^{\mathrm{a}}$} & \multicolumn{3}{|c|}{ Frequency } & \multirow[t]{2}{*}{$\mathrm{P}^{\mathrm{b}}$} & \multicolumn{3}{|c|}{ Distress } & \multirow[t]{2}{*}{$\mathrm{P}^{\mathrm{b}}$} \\
\hline & Medications & No & Yes & & Medications & No & Yes & \\
\hline \multirow{4}{*}{$\begin{array}{l}\text { Seizures }^{c} \\
(n=109)\end{array}$} & Almost never: & 3 & 6 & \multirow{4}{*}{$<.01$} & None or a little bit: & 5 & 17 & \multirow{4}{*}{.37} \\
\hline & Sometimes: & 8 & 37 & & Somewhat: & 4 & 24 & \\
\hline & Most of the time: & 1 & 48 & & A lot: & 3 & 39 & \\
\hline & Unsure/Can't tell: & 2 & 4 & & Unsure/Can't tell: & 2 & 14 & \\
\hline \multirow{4}{*}{$\begin{array}{l}\text { Pain }^{\mathrm{d}} \\
(\mathrm{n}=147)\end{array}$} & Almost never: & 3 & 1 & \multirow{4}{*}{.17} & None or a little bit: & 3 & 2 & \multirow{4}{*}{.1} \\
\hline & Sometimes: & 50 & 19 & & Somewhat: & 52 & 12 & \\
\hline & Most of the time: & 38 & 22 & & A lot: & 42 & 26 & \\
\hline & Unsure/Can't tell: & 13 & 1 & & Unsure/Can't tell: & 7 & 3 & \\
\hline \multirow{4}{*}{$\begin{array}{l}\text { Feeding } \\
\text { difficulties }^{\mathrm{e}} \\
(\mathrm{n}=129)\end{array}$} & Almost never: & 3 & 8 & \multirow{4}{*}{.26} & None or a little bit: & 9 & 17 & \multirow{4}{*}{.27} \\
\hline & Sometimes: & 10 & 25 & & Somewhat: & 18 & 21 & \\
\hline & Most of the time: & 35 & 46 & & A lot: & 14 & 37 & \\
\hline & Unsure/Can't tell: & 0 & 2 & & Unsure/Can't tell: & 6 & 7 & \\
\hline \multirow{4}{*}{$\begin{array}{l}\text { Constipation }^{\mathrm{f}} \\
(\mathrm{n}=126)\end{array}$} & Almost never: & 4 & 3 & \multirow{4}{*}{.3} & None or a little bit: & 8 & 3 & \multirow{4}{*}{.15} \\
\hline & Sometimes: & 29 & 18 & & Somewhat: & 23 & 13 & \\
\hline & Most of the time: & 34 & 38 & & A lot: & 29 & 36 & \\
\hline & Unsure/Can't tell: & 0 & 0 & & Unsure/Can't tell: & 6 & 6 & \\
\hline
\end{tabular}

Numbers reported as frequency.

${ }^{\text {a }}$ Sample size for each symptom is the number of times parents reported on frequency or distress of a symptom for their child at baseline.

${ }^{\mathrm{b}} \chi^{2}$ tests used for all comparisons.

${ }^{\mathrm{c}}$ Medications considered to be associated with management of seizures: anticonvulsants.

${ }^{\mathrm{d}}$ Medications considered to be associated with management of pain: NSAIDS, Acetaminophen, anesthetics; counted as 'yes' if any of these medications used.

${ }^{\mathrm{e}}$ Medications considered to be associated with management of feeding difficulties: antacids, prokinetics, antiemetics; counted as 'yes' if any of these medications used.

${ }^{\mathrm{f}}$ Medications considered to be associated with management of constipation: laxatives. 
Table 6: Relationships Between Presence of G/J Tube and Presence of Symptoms at Baseline for 275 Children With Progressive, Non-Curable Conditions

\begin{tabular}{|c|c|c|}
\hline Symptom $^{\mathrm{a}}$ & $\begin{array}{c}\text { G/J Tube Present } \\
\text { No Yes }\end{array}$ & $\mathrm{P}^{\mathrm{b}}$ \\
\hline Respiratory or breathing problems $(\mathrm{n}=270)$ & & \\
\hline No & 84 & $<.001$ \\
\hline Yes & 41 & \\
\hline Pain $(n=270)$ & & \\
\hline No & 67 & $<.01$ \\
\hline Yes & 58 & \\
\hline Feeding difficulties $(\mathrm{n}=271)$ & & \\
\hline 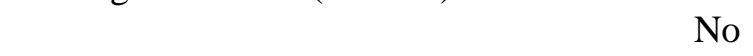 & 76 & $<.01$ \\
\hline Yes & 49 & \\
\hline Constipation $(n=270)$ & & \\
\hline No & 76 & $<.05$ \\
\hline Yes & 79 & \\
\hline Seizures $(n=271)$ & & \\
\hline No & 82 & .07 \\
\hline Yes & 66 & \\
\hline Sleep problems $(n=271)$ & & \\
\hline No & 69 & .1 \\
\hline $\begin{array}{rr}\text { Yes } \\
\end{array}$ & 56 & \\
\hline Alertness and interaction changes $(\mathrm{n}=271)$ & & \\
\hline No & 92 & .39 \\
\hline Yes & 54 & \\
\hline Total \# symptoms $(\mathrm{n}=271)$ & 125 & $<.001$ \\
\hline
\end{tabular}

Numbers reported as frequency.

${ }^{a}$ Sample size for each symptom is the number of times parents reported on presence of a symptom for their child at baseline.

${ }^{\mathrm{b}} \chi^{2}$ tests were used for the categorical variables; two-sample t-test was used for the continuous variable. 
Table 7: Relationships Between Presence of G/J Tube and Frequency \& Distress for Symptoms Present at Baseline in 275 Children With Progressive, Non-Curable Conditions

\begin{tabular}{|c|c|c|c|c|c|c|c|c|}
\hline \multirow[t]{2}{*}{ Symptom $^{\mathrm{a}}$} & \multicolumn{3}{|c|}{ Frequency } & \multirow[t]{2}{*}{$\mathrm{P}^{\mathrm{b}}$} & \multicolumn{3}{|c|}{ Distress } & \multirow[t]{2}{*}{$\mathrm{P}^{\mathrm{b}}$} \\
\hline & G/J tube Present & $\mathrm{No}$ & Yes & & G/J tube Present & No & Yes & \\
\hline \multirow{4}{*}{$\begin{array}{l}\text { Respiratory or } \\
\text { breathing } \\
\text { problems } \\
(\mathrm{n}=125)\end{array}$} & Almost never: & 2 & 3 & \multirow{4}{*}{.84} & None or a little bit: & 7 & 9 & \multirow{4}{*}{$<.05$} \\
\hline & Sometimes: & 20 & 39 & & Somewhat: & 16 & 25 & \\
\hline & Most of the time: & 18 & 42 & & A lot: & 10 & 46 & \\
\hline & Unsure/Can't tell: & 0 & 1 & & Unsure/Can't tell: & 6 & 4 & \\
\hline \multirow{4}{*}{$\begin{array}{l}\text { Pain } \\
(n=148)\end{array}$} & Almost never: & 1 & 3 & \multirow{4}{*}{.36} & None or a little bit: & 4 & 1 & \multirow{4}{*}{$<.05$} \\
\hline & Sometimes: & 31 & 39 & & Somewhat: & 27 & 37 & \\
\hline & Most of the time: & 19 & 41 & & A lot: & 20 & 49 & \\
\hline & Unsure/Can't tell: & 7 & 7 & & Unsure/Can't tell: & 6 & 4 & \\
\hline \multirow{4}{*}{$\begin{array}{l}\text { Feeding } \\
\text { difficulties } \\
(\mathrm{n}=129)\end{array}$} & Almost never: & 3 & 8 & \multirow{4}{*}{.86} & None or a little bit: & 13 & 13 & \multirow{4}{*}{$<.05$} \\
\hline & Sometimes: & 13 & 22 & & Somewhat: & 19 & 20 & \\
\hline & Most of the time: & 32 & 49 & & A lot: & 12 & 39 & \\
\hline & Unsure/Can't tell: & 1 & 1 & & Unsure/Can't tell: & 5 & 8 & \\
\hline \multirow{4}{*}{$\begin{array}{l}\text { Constipation } \\
(\mathrm{n}=127)\end{array}$} & Almost never: & 3 & 4 & \multirow{4}{*}{.89} & None or a little bit: & 6 & 5 & \multirow{4}{*}{.16} \\
\hline & Sometimes: & 17 & 31 & & Somewhat: & 17 & 19 & \\
\hline & Most of the time: & 28 & 44 & & A lot: & 23 & 43 & \\
\hline & Unsure/Can't tell: & 0 & 0 & & Unsure/Can't tell: & 2 & 10 & \\
\hline \multirow{4}{*}{$\begin{array}{l}\text { Alertness and } \\
\text { interaction } \\
\text { changes } \\
(\mathrm{n}=93)\end{array}$} & Almost never: & 3 & 1 & \multirow{4}{*}{.25} & None or a little bit: & 12 & 16 & \multirow{4}{*}{.25} \\
\hline & Sometimes: & 27 & 30 & & Somewhat: & 13 & 9 & \\
\hline & Most of the time: & 8 & 19 & & A lot: & 10 & 15 & \\
\hline & Unsure/Can't tell: & 2 & 2 & & Unsure/Can't tell: & 5 & 13 & \\
\hline \multirow{4}{*}{$\begin{array}{l}\text { Sleep } \\
(n=134)\end{array}$} & Almost never: & 3 & 3 & \multirow{4}{*}{.51} & None or a little bit: & 13 & 21 & \multirow{4}{*}{.37} \\
\hline & Sometimes: & 19 & 20 & & Somewhat: & 3 & 25 & \\
\hline & Most of the time: & 33 & 55 & & A lot: & 20 & 27 & \\
\hline & Unsure/Can't tell: & 0 & 1 & & Unsure/Can't tell: & 9 & 6 & \\
\hline \multirow{4}{*}{$\begin{array}{l}\text { Seizures } \\
(\mathrm{n}=109)\end{array}$} & Almost never: & 4 & 5 & \multirow{4}{*}{.62} & None or a little bit: & 7 & 15 & \multirow{4}{*}{.44} \\
\hline & Sometimes: & 20 & 25 & & Somewhat: & 13 & 15 & \\
\hline & Most of the time: & 16 & 33 & & A lot: & 18 & 24 & \\
\hline & Unsure/Can't tell: & 3 & 3 & & Unsure/Can't tell: & 4 & 12 & \\
\hline
\end{tabular}

Numbers reported as frequency.

${ }^{a}$ Sample size for each symptom is the number of times parents reported on frequency or distress of a symptom for their child at baseline.

${ }^{\mathrm{b}} \chi^{2}$ tests used for all comparisons. 
Table 8: Outcome Measure Results for 275 Children With Progressive, Non-Curable Conditions: Pediatric Evaluation of Disability Inventory

\begin{tabular}{|c|c|c|c|}
\hline PEDIC: Parts I, II, \& III and domains & Ill Children $^{\mathrm{a}}$ & $\begin{array}{c}\mathrm{p}^{\mathrm{b}}: \\
\text { conditions }\end{array}$ & $\begin{array}{l}p^{c}: \\
\text { gender }\end{array}$ \\
\hline Functional skill: Self-care $(\mathrm{n}=270)$ & $14.7 \pm 19.6$ & $<.001$ & .23 \\
\hline Functional skill: Mobility $(\mathrm{n}=270)$ & $14.6 \pm 19.2$ & $<.001$ & .65 \\
\hline Functional skill: Social function $(\mathrm{n}=270)$ & $16.9 \pm 18$ & $<.001$ & .44 \\
\hline Caregiver assistance: Self-care $(\mathrm{n}=270)$ & $4.7 \pm 9.7$ & $<.001$ & .11 \\
\hline Caregiver assistance: Mobility $(n=269)$ & $6.5 \pm 11.1$ & $<.001$ & .63 \\
\hline Caregiver assistance: Social function $(\mathrm{n}=270)$ & $4.1 \pm 6.8$ & $<.001$ & .62 \\
\hline \multicolumn{4}{|l|}{ Modifications: Self-care $(\mathrm{n}=270)$} \\
\hline No modifications & $3.9 \pm 2.2$ & $<.01$ & .55 \\
\hline $\begin{array}{l}\text { Child-oriented (non-specialized) } \\
\text { modifications }\end{array}$ & $3.0 \pm 2$ & $<.01$ & .49 \\
\hline Rehabilitation equipment & $0.4 \pm 0.8$ & .22 & .05 \\
\hline Extensive modifications & $0.7 \pm 1.1$ & .05 & .14 \\
\hline \multicolumn{4}{|l|}{ Modifications: Mobility $(\mathrm{n}=270)$} \\
\hline No modifications & $4 \pm 2.3$ & .001 & .26 \\
\hline $\begin{array}{l}\text { Child-oriented (non-specialized) } \\
\text { modifications }\end{array}$ & $1 \pm 1.6$ & .01 & .51 \\
\hline Rehabilitation equipment & $0.6 \pm 1.2$ & .30 & .68 \\
\hline Extensive modifications & $1.4+2.2$ & .001 & .67 \\
\hline \multicolumn{4}{|l|}{ Modifications: Social function $(\mathrm{n}=270)$} \\
\hline No modifications & $4.5 \pm 1.2$ & $<.01$ & .65 \\
\hline $\begin{array}{l}\text { Child-oriented (non-specialized]) } \\
\text { modifications }\end{array}$ & $0.1 \pm 0.4$ & .33 & .62 \\
\hline Rehabilitation equipment & $0.2+0.8$ & .04 & .25 \\
\hline Extensive modifications & $0.2+0.7$ & .42 & .89 \\
\hline
\end{tabular}

${ }^{\text {a }}$ Plus-minus values are means \pm SD.

b 1-way ANOVA was used for all continuous variables to test by children's conditions.

${ }^{\mathrm{c}}$ Two-sample t-test was used for all continuous variables to test by gender. 
Table 9: Relationships Between Functional Skills, Presence of G/J Tube, Highest Level of Mobility Modification Required, and Total Number of Symptoms Present at Baseline in 275 Children With Progressive, Non-Curable Conditions

\begin{tabular}{|c|c|c|c|}
\hline PEDI@-G/J Tube Variables & \multicolumn{2}{|c|}{ Test Statistics } & $\mathrm{P}$ \\
\hline $\begin{array}{l}\text { Functional skills }- \text { Self-care }(\text { Raw score })^{\mathrm{a}} \\
(\mathrm{n}=271)\end{array}$ & \multicolumn{2}{|c|}{ Total \# symptoms; $r=-.287$} & $<.001$ \\
\hline $\begin{array}{l}\text { Functional skills - Mobility (Raw score })^{\mathrm{a}} \\
(\mathrm{n}=271)\end{array}$ & \multicolumn{2}{|c|}{ Total \# symptoms; $r=-.297$} & $<.001$ \\
\hline $\begin{array}{l}\text { Functional skills - Social function (Raw score) }{ }^{\mathrm{a}} \\
(\mathrm{n}=271)\end{array}$ & \multicolumn{2}{|c|}{ Total \# symptoms; $r=-.21$} & .001 \\
\hline $\begin{array}{l}\text { PEDIC: Highest level of mobility modifications }{ }^{\mathrm{b}, \mathrm{c}} \\
(\mathrm{n}=270)\end{array}$ & $\begin{array}{l}\text { G/J tube present } \\
\text { None: } \\
\text { Child: } \\
\text { Rehab: } \\
\text { Extensive: } \\
\chi^{2}=27.39 ; \mathrm{df}=\end{array}$ & $\begin{array}{cc}\text { No } & \text { Yes } \\
30 & 31 \\
39 & 28 \\
27 & 13 \\
27 & 75 \\
\end{array}$ & $<.001$ \\
\hline $\begin{array}{l}\text { Interaction of Highest level of mobility } \\
\text { modifications \& G/J tube present or not }{ }^{\mathrm{d}}\end{array}$ & $\begin{array}{l}\text { Total \# symptom } \\
\mathrm{F}=1.686 ; \mathrm{df}=3\end{array}$ & & .17 \\
\hline PEDI@: Highest level of mobility modifications ${ }^{\mathrm{d}}$ & $\begin{array}{l}\text { Total \# symptom } \\
\mathrm{F}=13.654 ; \mathrm{df}=\end{array}$ & & $<.001$ \\
\hline $\mathrm{G} / \mathrm{J}$ tube present or not ${ }^{\mathrm{d}}$ & $\begin{array}{l}\text { Total \# symptom } \\
\mathrm{F}=4.866 ; \mathrm{df}=3\end{array}$ & & $<.01$ \\
\hline
\end{tabular}

Numbers reported as frequency.

${ }^{a}$ Pearson correlation between functional skills and total number of symptoms at baseline.

${ }^{\mathrm{b}}$ Highest level determined by presence of a positive response on at least one of the PEDI modification questions, where None is lowest level possible and Extensive is highest level possible.

${ }^{c} \chi^{2}$ test used for comparison between highest level of mobility modifications and presence of G/J tube at baseline.

d 2-way ANOVA with highest level of mobility modifications and presence of G/J tube as the 2 factors, and total number of symptoms as the response variable. 